\title{
Erratum to: Peritoneal Sarcomatosis: Is There a Subset of Patients Who May Benefit from Cytoreductive Surgery and Hyperthermic Intraperitoneal Chemotherapy?
}

Dario Baratti, MD ${ }^{1}$, Elisabetta Pennacchioli, $\mathrm{MD}^{2}$, Shigeki Kusamura, $\mathrm{PhD}^{1}$, Marco Fiore, $\mathrm{MD}^{2}$, Maria Rosaria Balestra, $\mathrm{MD}^{1}$, Chiara Colombo, $\mathrm{MD}^{2}$, Elvira Mingrone, $\mathrm{MD}^{1}$, Alessandro Gronchi, $\mathrm{MD}^{2}$, and Marcello Deraco, $\mathrm{MD}^{1}$

${ }^{1}$ Peritoneal Malignancy Program, Department of Surgery, National Cancer Institute, Milan, Italy; ${ }^{2}$ Sarcoma Unit, Department of Surgery, National Cancer Institute, Milan, Italy

\section{ERRATUM TO: ANN SURG ONCOL} DOI 10.1245/S10434-010-1178-X

The author byline of the published article entitled "Peritoneal Sarcomatosis: Is There a Subset of Patients Who May Benefit from Cytoreductive Surgery and Hyperthermic Intraperitoneal Chemotherapy?" included an error in the spelling of the following author's name: Gronchi A ("Alessandro G" was incorrectly published).

The correct byline for this article is as follows:

Baratti D, Pennacchioli E, Kusamura S, Fiore M, Balestra MR, Colombo C, Mingrone E, Gronchi A, Deraco M

Alessandro Gronchi and Marcello Deraco contributed equally to the paper.

The online version of the original article can be found under doi:10.1245/s10434-010-1178-x.

(C) Society of Surgical Oncology 2010

Published Online: 23 October 2010

M. Deraco, MD

e-mail: marcello.deraco@istitutotumori.mi.it 